\title{
ATTRACTING PRIVATE INVESTMENT INTO REDD+ PROJECTS: AN OVERVIEW OF REGULATORY CHALLENGES
}

Dr Sophie Chapman

Department of Land Economy

University of Cambridge ${ }^{1}$

Martijn Wilder AM

Partner

Baker \& McKenzie

To date, forest carbon projects around the world have faced common challenges within what are nonetheless unique, country-specific legal and political systems. These issues include the role of land tenure in forest carbon projects, the importance of legal frameworks in clarifying the legal foundations for forest carbon projects (such as with respect to the right to carbon or the process under which forest carbon projects can be approved) and the need to properly address leakage, additionality, permanence, and community and biodiversity benefits within forest carbon project design. By addressing these issues, both international and national regulation has a role to play in creating the enabling conditions for private sector investment.

This paper will provide an overview of the regulatory issues that need to be addressed to enable private sector investment into REDD+ projects by 1) outlining current international policy, noting the role of the private sector in REDD+ implementation and describing the voluntary market's role as a testing ground for early forest carbon projects; 2) discussing REDD+ implementation from a projectlevel perspective, including both the general and legal issues that need to be addressed in REDD+ project design; and 3) considering how these lessons (drawn largely from land-based forest carbon projects) apply to mangroves, peatlands and other wetlands as sites for implementing REDD+ activities.

\section{Introduction}

REDD+, an initiative concerned with 'Reducing Emissions from Deforestation and Forest Degradation in developing countries, and the role of conservation, sustainable management of forests and enhancement of forest carbon stocks in developing countries' (REDD+) has emerged out of the United Nations Framework Convention on Climate Change ('UNFCCC')/Kyoto Protocol negotiations. ${ }^{2}$ It is an international initiative that acknowledges the role of private sector participation to finance its implementation ${ }^{3}$; the exact details of the REDD+ mechanism are still being debated, and whether it will be able to generate tradable carbon credits for sale in global carbon markets will continue to be discussed as part of the international climate change negotiations. In addition, governments that are developing domestic emissions trading schemes still need to confirm the extent to which REDD+-based credits will be accepted as a means of meeting carbon emission compliance obligations. In parallel to these policy developments, a major driver of forest carbon

\footnotetext{
1 The authors would like to acknowledge the invaluable contributions of Beth Dooley and Gretchen Engbring, who both hold the position of Programme Officer at the Cambridge Centre for Climate Change Mitigation Research (University of Cambridge).

2 REDD was introduced on the agenda at the $11^{\text {th }}$ Conference of the Parties (COP) to the UNFCCC in Montreal during 2005. Two years later, Decision 2/CP.13 (part of the Bali Road Map called 'Reducing Emissions from Deforestation in Developing Countries: Approaches to Stimulate Action') was reached. At COP14 in Poznań, the concept of REDD+ was introduced to integrate 'the role of conservation, sustainable management of forests and enhancement of forest carbon stocks in developing countries' into the existing policy framework to reduce emissions from deforestation and forest degradation (See UNFCCC, Background: REDD <http://unfccc.int/methods_science/redd/items/4547.php>. The Cancun Agreements laid out the policy framework for REDD+ to develop based on the work of the AWG-LCA (Ad hoc Working Group on Long-term Cooperative Action under the Convention). See UNFCCC, The Cancun Agreements: Outcome of the Work of the Ad Hoc Working Group on Long-Term Cooperative Action Under the Convention, Decision $1 /$ CP.16, FCCC/CP/2010/7/Add 112 .

3 UNFCCC, The Durban Platform: Outcome of the Work of the Ad Hoc Working Group on Long-Term Cooperative Action Under the Convention (AWG-LCA), Decision 2/CP.17 § II(C).
} 
investment to date, the voluntary market, ${ }^{4}$ has facilitated the development of numerous forest carbon projects. Forest carbon projects have also been developed under the Clean Development Mechanism (CDM) ${ }^{5}$ and domestic schemes such as the New South Wales Greenhouse Gas Reduction Scheme (NSW GGAS). ${ }^{6}$ These voluntary projects provide insight into the practical challenges for REDD+ implementation; given that private sector finance will be necessary to scale-up REDD + implementation, insights regarding the legal frameworks required to support private sector investment is valuable. This paper is written from a projectlevel, private sector perspective and draws on practical experience from working on early forest carbon projects and transactions in the voluntary market, under the CDM and also under domestic trading schemes. Irrespective of the model adopted for future REDD+ schemes (whether a project-based or national approach, or a combination of the two), common issues with respect to the legal foundations of REDD+ initiatives will need to be addressed.

Forest carbon projects around the world have faced common challenges within what are nonetheless unique, country-specific legal and political systems. These issues include the role of land tenure in forest carbon projects, the importance of legal frameworks in clarifying the legal foundations for forest carbon projects (such as with respect to the right to carbon or the process under which forest carbon projects can be approved) and the need to properly address leakage, additionality, permanence, and community and biodiversity benefits within forest carbon project design. By addressing these issues, both international and national regulation have a role to play in creating the enabling conditions for private sector investment.

This paper will provide an overview of the regulatory issues that need to be addressed to enable private sector investment into REDD+ projects by: 1) outlining current international policy, noting the role of the private sector in REDD + implementation and describing the voluntary market's role as a testing ground for early forest carbon projects; 2) discussing REDD+ implementation from a project-level perspective, including both the general and legal issues that need to be addressed in REDD+ project design; and 3) considering how these lessons (drawn largely from land-based forest carbon projects) apply to mangroves, peatlands and other wetlands as sites for implementing REDD+ activities.

\section{Background: REDD+, law and the private sector International policy development regarding REDD+}

Deforestation and forest degradation account for nearly $20 \%$ of global greenhouse gas emissions. ${ }^{7}$ Drivers which may accelerate these processes are agricultural expansion, pastureland conversion, development of infrastructure, excessive logging and forest fires. ${ }^{8}$ The global community has recognised the need to stabilise global average temperatures to an increase of no more than two degrees celsius. ${ }^{9}$ In order to achieve such reductions, emissions from the forest sector must be targeted in addition to other mitigation actions.

\footnotetext{
${ }^{4}$ The voluntary Over-The-Counter (OTC) offset market refers to all voluntary sales and purchases of carbon credits (mostly project-based emissions reductions credits) outside of the Chicago Climate Exchange. For more information about the Chicago Climate Exchange, see <https://www.theice.com/ccx.jhtml>. For more information about the OTC offset market, see <http://www.ecosystemmarketplace.com/pages/dynamic/web.page.php?section=carbon_ market\&page_name $=$ otc_market $>$.

The market-based Clean Development Mechanism (CDM) is an international regime established under the Kyoto Protocol to the UNFCCC, implemented at the national level (largely by the private sector). Kyoto Protocol, art 12: '(1) A clean development mechanism is hereby defined, (2) The purpose of the clean development mechanism shall be to assist parties not included in Annex I in achieving sustainable development and in contributing to the ultimate objective of the UNFCCC, and to assist parties included in Annex I in achieving compliance with their quantified emissions limitations and reduction commitments under Article 3'. Kyoto Protocol to the United Nations Framework Convention on Climate Change, Kyoto, Japan, 11 December 1997, 2303 UNTS 148 (entered into force 16 February 2005) ['Kyoto Protocol'].

6 The New South Wales Greenhouse Gas Reduction Scheme (NSW GGAS), now closed, commenced operating in 2003 as a state-level initiative in Australia. It was one of the first mandatory greenhouse gas emissions trading schemes in the world. It aimed to reduce greenhouse gas emissions associated with the production and use of electricity, designed to achieve this by using project-based activities to offset the production of greenhouse gas emissions - see <http://www.greenhousegas.nsw.gov.au/>. A current Australian scheme called the Carbon Farming Initiative (CFI) aims to allow farmers and land managers to earn carbon credits by storing carbon or reducing greenhouse gas emissions on the land, which can then be sold to people and businesses wishing to offset their emissions - see <http://www.climatechange.gov.au/reducing-carbon/carbon-farming-initiative>

7 UN-REDD Programme, About REDD+ <http://www.un-redd.org/aboutredd/tabid/582/default.aspx>. Ibid.

UNFCCC Cancun Agreements, above n 2, § I(4).
} 
Reducing Emissions from Deforestation and Forest Degradation (REDD) was designed to put a price on carbon stored in forests and thereby incentivise developing countries to reduce emissions from forests. Funds generated from the stored forest carbon could then be invested in low-carbon paths to sustainable development. ${ }^{10}$ REDD + was developed to extend beyond deforestation and forest degradation to include 'the role of conservation, sustainable management of forests and enhancement of forest carbon stocks in developing countries' as additional policy objectives in reducing emissions from forests. ${ }^{11}$ REDD+ is developing rapidly through efforts directed toward finalising the international rules under the UNFCCC/Kyoto Protocol, ${ }^{12}$ and the public and private monies flowing into safeguarding forest protection with the potential to generate carbon returns. At COP-16 in Cancun, Mexico, parties agreed to establish a mechanism for REDD $+;^{13}$ at COP-17 in Durban, further advancement was made with recognition of the desire for private sector participation in financing the implementation. ${ }^{14}$ The exact details of that mechanism are still being debated and the actual approach to REDD+ (for example, whether developing countries will implement it solely at the national level or incorporate regions and project-based activities into their accounting frameworks - called 'nesting') remains to be determined. In addition, further discussions about whether the mechanism will be able to generate tradable carbon credits (REDD+ credits) for sale in global carbon markets will be a key focus of the ongoing international climate change negotiations, while individual governments that are developing domestic emissions trading schemes still need to confirm the extent to which REDD+-based credits will be accepted as a means of meeting compliance obligations.

\section{The private sector and REDD+}

The finance required to halve emissions from the forest sector by 2030 could be around US\$17-33 billion per year, ${ }^{15}$ with a role for both the public and private sectors. ${ }^{16}$ In addition, developing countries will need substantial support for capacity building. ${ }^{17}$ Commentators have, therefore, argued that private sector engagement and investment is critical for the launch, growth, and maintenance of REDD ${ }^{18}$; some believe that private investment must be 'mobilised if the targets for REDD+ are to be achieved'. ${ }^{19}$

There is potential for the private sector to engage with REDD+ as investors through project financing, producers through project development and implementation, brokers through carbon credit trading and retailing, advisors through technical expertise and capacity building, auditors through validation and certification, and end buyers through carbon credit purchasing. ${ }^{20}$ However, REDD+ projects present a number of implementation, financial, political, natural disturbance and methodological risks that investors must assess and minimise. ${ }^{21}$ Even in the face of these persistent barriers, the private sector has already played a significant role in the development of REDD+ and is already a major investor in the forestry sector. ${ }^{22}$ In 2011, a number of private REDD + investment funds were established, including Althelia (US

\footnotetext{
${ }^{10}$ UN-REDD Programme, above $\mathrm{n} 7$.

11 UNFCCC Cancun Agreements, above n 2, § I(C).

12 See text, above $\mathrm{n} 2$.

${ }^{13}$ UNFCCC Cancun Agreements, above n 2 § III(C) paras 71-78 App I-II.

${ }^{14}$ UNFCCC Durban Platform, above n 3, § II(C).

15 Johan Eliasch, 'Climate Change: Financing Global Forests' (Review commissioned by UK Government, 2008) xvi, para 4 <http://www.official-documents.gov.uk/> document/other/9780108507632/9780108507632.pdf> ('Eliasch Review'). The range here is dependent upon the level of rent received by forest nations, see ibid.

${ }^{16}$ Ibid xix, para 1.

17 Ibid xiii, para 4.

${ }^{18}$ See, eg, Florence Bernard, Scott McFatridge and Peter A Minang, 'The Private Sector in the REDD+ Supply Chain: Trends, Challenges and Opportunities' (IISD Policy Brief, 2012) 1, 3 <http://www.iisd.org/pdf/2012/redd_private_ sector_report.pdf>; Eliasch Review, above n 15; Forum for the Future, 'Forest Investment Review' (Commissioned by UK's Department of International Development (DFID) and Department of Energy and Climate Change (DECC), July 2009) 13-16 <http://www.forumforthefuture.org/sites/default/files/project/downloads/forestinvestmentreviewfull. pdf>; Mark Lambert, 'Mitigating Risk to Catalyze Private Investment in REDD', (Presentation at GCF Taskforce Meeting, September 2011) <http: / /www.gcftaskforce.org/meeting/documents/Mark_Lambert_Terra_Global_Capital.pdf>; R O'Sullivan et al, 'Engaging the Private Sector in the Potential Generation of Carbon Credits from REDD+: An Analysis of Issues' (Report to the UK Dept for International Development (DFID), 4 August 2010) 8, 51 <http: //www.conservation finance.org/upload/library/arquivo20100806090349.pdf; Phil Ovitt, 'Private Sector Opportunities Under Various REDD Scenarios' (Presentation to the Organization for Tropical Studies-International Forest Carbon for US Decision Makers Course, 2009) <http://nicholasinstitute.duke.edu/ecosystem/redd-policy-options-courses-and-conversationsots/Private_Sector_Opportunitites_Under_Various_REDD_Scenarios.pdf>.

${ }^{19}$ Forum for the Future, above n 18, 14, para 5.

${ }^{20}$ Bernard et al, above n 18.

${ }^{21}$ Lambert, above $\mathrm{n} 18$.

22 O'Sullivan et al, above n 18, 51.
} 
\$275 million target capitalisation), Macquarie-International Finance Corporation (US\$25 million) and Terra Global Capital (US\$50 million). ${ }^{23}$

Among other factors, to invest at scale, the private sector requires clearly defined property rights, enforceable contracts, effective institutions, and transparent and reliable approval procedures. ${ }^{24}$ Therefore, policy-makers and regulators can play a large role in encouraging private sector investment by creating stable legal foundations for projects.

\title{
The voluntary market for forest carbon \\ Background
}

Many forest carbon projects have been developed to generate credits for sale in the voluntary market. For governments, corporations, organisations and individuals concerned with the detrimental effects of rising levels of atmospheric carbon, carbon markets may provide one (often controversial) means by which to maximise carbon reductions while minimising associated costs. ${ }^{25}$ In mandatory or 'cap and trade' carbon markets created by greenhouse gas (GHG) reduction regimes like the Kyoto Protocol ${ }^{26}$ :

\begin{abstract}
Emission permits - corresponding to a cap fixed by the regulator - are initially distributed among the participants to the system, and emitters included in the system eventually have to cover their emissions by a sufficient number of permits. Participants may offset their excess emissions by acquiring permits from other sources able and willing to emit below their established cap. Each incremental emission has a price fixed by the permit market. Inversely, emitters willing to emit below their cap can directly benefit from the carbon price by selling unused permits. ${ }^{27}$
\end{abstract}

However, carbon markets may also be motivated by non-regulatory factors such as corporate GHG reduction targets, resale or investment potential, pre-compliance with predicted regulations, public relations or branding efforts, or direct concerns for climate change. ${ }^{28}$ In instances where emissions reductions are not mandatory but driven by a host of other factors, voluntary carbon markets may emerge that is, 'markets through which firms, individuals and organizations voluntarily buy emissions reduction credits to counterbalance their net carbon emissions'. ${ }^{29}$

In such voluntary carbon markets, an emissions reduction credit, or offset, may be defined as 'an instrument representing the reduction, avoidance, or sequestration' of a designated amount (often one metric tonne) of carbon dioxide $\left(\mathrm{CO}_{2}\right)$ or greenhouse gas equivalent. ${ }^{30}$ As forests and their soils have a high carbon sequestration and storage capacity, ${ }^{31}$ their conservation, restoration and management offer considerable (though not uncomplicated) opportunities for projects that reduce, avoid or sequester carbon emissions, ${ }^{32}$ and so generate emissions reduction credits. When a contract is signed between a seller and a buyer to deliver these credits in exchange for funds, a 'transaction' takes place. ${ }^{33}$ Cumulatively, these forest-generated credit transactions constitute the voluntary forest carbon market.

Within the voluntary forest carbon market, or 'over the counter' (OTC) market, projects that reduce, avoid or sequester carbon emissions must adhere to independent, international or domestic standards in order to generate certified credits that appeal to buyers. A standard is a 'set of project design, monitoring and reporting criteria to which carbon offsetting activities and/or projects' environmental, social and other cobenefits can be certified or verified'. ${ }^{34}$ Within the voluntary forest carbon market, 'a number of competing

\footnotetext{
23 Toby Janson-Smith and H Marsh, A Corporate Primer on Reducing Emissions from Deforestation and Forest Degradation (REDD): The Context, Key Technical and Policy Issues, and Private Sector Involvement (Conservation International, 2012).

${ }^{24}$ Ovitt, above $\mathrm{n} 18$.

${ }^{25}$ Anaïs Delbosc and Christian de Perthuis, Carbon Markets: The Simple Facts (United Nations Global Compact, 2009) <http://www.unglobalcompact.org/docs/issues_doc/Environment/Carbon_Markets_The_Simple_Facts.pdf>.

${ }^{26}$ Kyoto Protocol, above n 5.

27 Delbosc and de Perthuis, above n 25, 10, para 4.

${ }^{28}$ Molly Peters-Stanley, Katherine Hamilton and Daphne Yin, 'Leveraging the Landscape: State of the Forest Carbon Markets 2012', (Ecosystem Marketplace/Forest Trends, 2012) vi, fig 6 <http://www.forest-trends.org/documents/files /doc 3242.pdf>.

29 Ibid xiv, para 8.

30 Ibid xiii, para 4.

${ }^{31}$ Yude Pan et al, 'A Large and Persistent Carbon Sink in the World’s Forests', (2011) 333 Science 988.

32 Ross Gorte and Jonathan Ramseur, Forest Carbon Markets: Potential and Drawbacks (2010) Congressional Research Service <http: //crs.ncseonline.org/NLE/CRSreports/10Jun/RL34560.pdf>.

${ }^{33}$ Peters-Stanley et al, above n 31, 3, para 2.

34 Ibid xiv, para 2.
} 
standards have emerged with the intent to increase credibility in the marketplace'. ${ }^{35}$ Only once a 'carbon offset project has been validated, verified and undergone other required processes' can carbon credits be 'issued to the project owner with a unique identifier; and tracked, transferred and retired by a designated registry'. ${ }^{36}$

A Forest Trends initiative, Ecosystem Marketplace, produces an annual report that summarises activity in the voluntary forest carbon market (based on responses from forest project developers and secondary market suppliers). ${ }^{37}$ The 2012 report reveals that:

- $\quad$ Private sector actors provided $67 \%$ of the forest carbon offset supply, possibly due to expectations regarding future and emerging compliance markets; ${ }^{38}$

- The value for forestry offsets in the global marketplace totalled some US \$237 million in 2011 - an increase from the previous year; ${ }^{39}$

- The market-wide average price in 2011 was US\$9.2/ $\mathrm{tCO}_{2} \mathrm{e}$, though prices ranged from less than US\$1/ $\mathrm{tCO}_{2} \mathrm{e}$ to over US\$100/ $\mathrm{tCO}_{2} \mathrm{e}$ based on project standards, location, and environmental and social co-benefits; ${ }^{40}$ and

- In 2011, the Voluntary Carbon Standard (now the Verified Carbon Standard) 'retained its top spot among independent standards that offer methodologies for a variety of project types and regions, capturing $28 \%$ of overall global market share for carbon accounting standards with $6.5 \mathrm{MtCO}_{2} \mathrm{e}$ transacted'. ${ }^{41}$

\section{Regulating projects developed under the voluntary market}

All forest carbon projects are implemented within the context of the domestic legal structures of their host countries, meaning that domestic regulations under land law, environmental law, investment law, contract law, tax law and potentially many other laws may apply. However, in the absence of compliance regimes that would prescribe the requirements a forest carbon project must meet in order to generate tradable credits (that is, if a project does not meet certain criteria or standards, it will not be able to generate credits), voluntary standards have developed as a non-regulatory instrument to provide guidance for project developers wishing to implement forest carbon activities. Given the complexity of developing forest carbon projects and the fact that they are often implemented in locations where regulatory uncertainty is high, voluntary standards can help to provide benchmarks for what forest carbon projects need to do in order to create robust, 'investment-grade' carbon offsets that can attract investment. There are many such voluntary standards, including the Verified Carbon Standard (VCS) and the Climate, Community and Biodiversity (CCB) Standard (discussed below).

\section{The Verified Carbon Standard (VCS)}

The VCS is an independent ${ }^{42}$ GHG programme that sets out the 'rules' for 'determining project eligibility, quantifying greenhouse gas emission reductions and issuing credits'. ${ }^{43} \mathrm{Here}$, a project specifically refers to a carbon project that seeks to 'implement activities that reduce or remove emissions'. ${ }^{44}$ The VCS is sometimes referred to as containing 'pre-compliance' requirements that have been developed with the expectation that the standards create a benchmark on which future regulation could be based.

Projects that participate in the VCS program are eligible to receive emissions reduction credits for their GHG reductions or removals, known as Verified Carbon Units (VCUs). ${ }^{45}$ These VCUs can then 'be bought by third parties wishing to offset, or compensate, their own GHG emissions'. ${ }^{46}$ The VCS programme provides that:

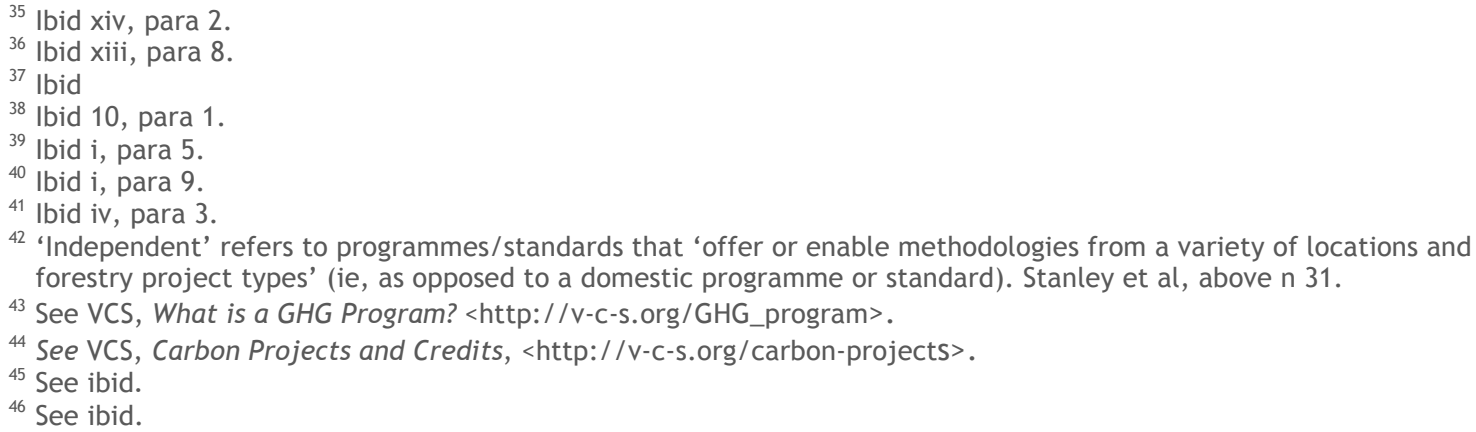


1. Projects must follow a set of quality assurance principles and requirements to ensure that 'emission reductions and credits generated are real, additional and third-party verified'. ${ }^{47}$ This includes a requirement for 'evidence of right of use': ${ }^{4}$

- Paragraph 3.17.2: 'For validation, the project proponent shall make available to the validation/verification body the project description, evidence of right of use and any requested supporting information and data needed to support statements and data in the project description and evidence of right of use';

- Paragraph 3.4.10(5): With respect to grouped projects, 'grouped projects provide for the inclusion of new project activity instances subsequent to the initial validation of the project. New project activity instances shall ... Have evidence of right of use, in respect of each project activity instance, held by the project proponent from the respective start date of each project activity instance (ie, the date upon which the project activity instance began reducing or removing GHG emissions)'.

2. Projects must meet 'specific eligibility criteria and follow pre-approved protocols for quantifying GHG emission reductions or removals' as established in a variety of different methodologies for specific project scenarios. ${ }^{49}$

3. 'All emission reductions and credits are professionally verified by approved validation/verification bodies (VVBs)'. 50

4. A secure and transparent registry system is available for issuing and tracking each Verified Carbon Unit (VCU). ${ }^{51}$

The VCS has 15 sectoral scopes or categories of activities that projects may be developed under. ${ }^{52}$ Within the 'Agriculture Forestry and Other Land Use' (AFOLU) sectoral scope, the VCS provides methodologies for six different project categories including Afforestation, Reforestation and Revegetation (ARR), Agricultural Land Management (ALM), Improved Forest Management (IFM), Reduced Emissions from Deforestation and Degradation (REDD), Avoided Conversion of Grasslands and Shrublands (ACoGS), and Wetlands Restoration and Conservation (WRC). ${ }^{53}$

Although the VCS is just one of many programmes providing standards and/or a registry within the voluntary forest carbon market, ${ }^{54}$ it is significant because it possesses the largest percentage of the market share among independent and domestic carbon accounting standards. ${ }^{55}$ In addition, the VCS is often paired with the Climate, Community and Biodiversity (CCB) Standard ${ }^{56}$ - a 'co-benefit' standard that is described more in the following section.

\section{The Climate, Community and Biodiversity (CCB) Standard}

The CCB Standard is an independent ${ }^{57}$ co-benefit standard developed by the Climate, Community, and Biodiversity Alliance (CCBA) to help ensure that forestry, agricultural and other land use activities are designed to 'deliver significant additional benefits to enhance the well-being of local people, to conserve biodiversity and to assist with adaptation to the effects of climate change'. ${ }^{58}$ However, the 'CCB Standards

\footnotetext{
${ }^{47}$ See VCS, above n 43.

${ }^{48}$ See Verified Carbon Standard, VCS Standard (Requirements Document, VCS Version 3.3, 4 October 2012) <http://v-cs.org/sites/v-c-s.org/files/VCS\%20Standard,\%20v3.3.pdf>.

${ }^{49}$ See ibid.

50 See ibid.

51 See ibid.

52 These scopes include energy (renewable/non-renewable), energy distribution, energy demand, manufacturing industries, chemical industry, construction, transport, mining/mineral production, metal production, fugitive emissions from fuels, fugitive emissions from industrial gases, solvents use, waste handling and disposal, Agriculture Forestry and Other Land Use (AFOLU) and livestock and manure management. See VCS, VCS Sectoral Scopes <http://vc-s.org/node/448>.

${ }^{53}$ See VCS, Agriculture and Forestry Projects <http://v-c-s.org/develop-project/agriculture-forestry-projects>.

${ }^{54}$ Peters-Stanley et al, above n 33, 29-35.

55 Ibid iv, para 3 and $v$, fig 4.

56 The VCS maintained $18 \%$ of the market share for independent and major co-benefit standards in 2011 , whereas the VCS and CCB combined capture another $12 \%$ of the market share. Peters-Stanley et al, above n 33, 30, fig.28.

57 'The Standards can be applied to any forestry, agriculture or other land use carbon project anywhere in the world, whether undertaken for compliance or for voluntary carbon-offsetting purposes', see, CCBA, CCB Standards Fact Sheet $<$ https://s3.amazonaws.com/CCBA/CCBStandards_FactSheet.pdf>.

${ }^{58}$ See ibid.
} 
used alone do not lead to delivery of quantified emissions reductions certificates so they should be used in combination with a carbon accounting standard (such as the VCS)' ${ }^{59}$

The CCB Standard involves a two-step process:

1. 'Validation demonstrates good project design to generate significant climate, community and biodiversity benefits'. ${ }^{60}$

5. 'Verification is a rigorous, independent endorsement of the quality of project implementation and the delivery of multiple benefits. Successful CCB Verification enables the addition of a "CCB label" to verified emissions reductions units such as VCUs'. ${ }^{61}$

The CCB Standard itself requires that projects must meet 17 discrete criteria categorised as 'general' requirements, 'climate' requirements, 'community' requirements, 'biodiversity' requirements and 'gold level' requirements (each requirement is detailed and described further in the standards to guide projects). ${ }^{62}$ To be approved, projects must meet all but the optional 'gold level' requirements. ${ }^{63}$ To receive 'gold level' validation, projects must additionally meet at least one of three 'gold level' criteria. ${ }^{64}$ Notably, the CCB Standard does not provide land type-specific methodologies (that is, for wetlands restoration and conservation) like the VCS. ${ }^{65}$

As of May 2011, 37 projects had completed validation under the CCB Standard, 14 projects had initiated the validation process, and two projects had achieved verification. ${ }^{66}$ In 2011 , the VCS-CCB standard pairing captured $12 \%$ of the market share for independent and major co-benefit standards. ${ }^{67}$

\section{REDD+ implementation from the bottom-up}

\section{What is a 'project-level' perspective'?}

This paper does not seek to advocate for either a market-based or project-level approach to REDD+ implementation, but draws on practical experience in the voluntary market and early compliance markets to provide an overview of the issues that can affect private sector investment into forest carbon projects and programmes. It must be noted that the development of individual projects for the voluntary market (or, indeed, future compliance markets) is the subject of debate for policy-makers (at both the international and national levels) with respect to issues such as safeguards and GHG accounting. Nonetheless, the voluntary forest carbon market has driven demand for forest carbon credits and, in so doing, private sector investment into forest carbon projects around the world.

From a project-level perspective, a project developer needs to ensure that, to the greatest extent possible, the project is developed based on strong legal foundations so that any risk of it being compromised in the future is minimised. A project developer also aims to ensure that any carbon credits generated will be capable of creating value and this, is turn, requires acceptance under national and international trading frameworks. This requires careful assessment of the national law and sub-national law that applies to 1) the land used, 2) the finance structure and ongoing management of the project activity, and 3) from the perspective of a carbon credit buyer, what future national trading schemes will require in order for such carbon credits to be eligible. While some early indications exists, such as in the case of California, the historical approach to generating carbon credits from forestry activities under the CDM and domestic trading regimes, such as those in Australia and New Zealand, provides significant assistance.

\section{General issues that REDD+ projects need to address}

In addition to legal issues (to be discussed next), 'investment-grade' projects need to successfully address a number of practical issues in order to create a robust 'carbon product' (a commodity) which will then be 'monetised' (given a price) within the market. A 'carbon credit' represents a quantity of carbon that is

\footnotetext{
59 See ibid.

60 See ibid.

61 See ibid.

${ }^{62}$ See CCBA, CCB Standards (2008) <http://www.climate-standards.org/standards/pdf/ccb_standards_second_edition _december_2008.pdf $>$.

63 See ibid.

${ }^{64}$ See ibid.

${ }^{65}$ See ibid.

${ }^{66}$ See CCBA, above n 57

${ }^{67}$ Peters-Stanley, above n 33, 30, fig 28.
} 
stored in the trees and land (and not emitted into the atmosphere); depending on the standard used to 'create' or validate the credit, the credit could also represent community benefits and biodiversity benefits. Whereas the 'carbon' value can be used towards a climate change commitment, community and biodiversity benefits are also attractive to an investor who wants to 'buy' a contribution to community empowerment and conservation. These general issues include:

1. Baselines and additionality: Emissions reductions must be 'additional' to those which would have occurred in the absence of the project. In order to determine whether and to what extent emissions reductions are 'additional', it is usually necessary to set a 'baseline' for the project (that is, a hypothetical reference case which represents the volume of GHGs that would have been emitted if the project were not implemented). ${ }^{68}$

2. Community and biodiversity benefits: In addition to climate change mitigation, project developers often seek to support regional governments and local communities with the skills, technology and financial resources to sustainably protect their natural environments and improve livelihoods through the sale of carbon and other ecosystem products. Investing an appropriate share of the project revenue in capacity building programs and enabling community participation in the ongoing maintenance of the project can help to ensure that carbon retention is both long-term and sustainable. $^{69}$

3. Leakage: In determining the project's baseline, project participants are generally required to take into account any 'leakage' that may be caused - that is, whether preventing emissions from the relevant landscape will simply cause another landscape to be used in an emissions-intensive activity. A project developer's approach to managing leakage will be guided by the requirements of the standard adopted. ${ }^{70}$

4. Permanence: For any transaction to succeed, the buyer will want assurance that the carbon stock they are purchasing will remain in place. Thus, 'permanence' refers to the extent to which a carbon sequestration project is able to achieve an absolute and irreversible reduction in the volume of carbon dioxide in the atmosphere. For a 'permanent' forestry credit to be created, there must be some kind of guarantee that the carbon sequestered will continue to be stored by the relevant landscape. Noting the many natural risks faced by landscapes, strategies to achieve this could include: imposing a period of mandatory maintenance and introducing legal tools to ensure that this is achieved; providing incentives for the project proponent to ensure permanence (which could be through a phased release of carbon rights, or preventing additional carbon rights from being generated if permanence is not maintained); or ensuring that, in the event there is a permanence failure, the system allows for rectification of that permanence failure through sourcing replacement credits or cancelling issued credits. ${ }^{71}$

\section{Legal issues that REDD+ projects need to address}

A major challenge for REDD+ implementation is that legal systems in host countries are yet to implement rules governing REDD+ activities and, in addition, must contend with institutional and administrative challenges. In the longer term, it would be extremely helpful if host country legal systems provided clear procedures to approve REDD+ activities in order to provide certainty regarding the creation of carbon credits and reduce long-term sovereign risk that, in the future, the project will be unwound or disallowed.

Therefore, in a transitional period where such laws are under development, from the perspective of both project developers and the investors looking to finance REDD+ projects, understanding national legal frameworks is an essential component of the due diligence process. In the absence of these rules, project developers, potential investors and potential buyers of carbon credits need to ensure emissions reductions are legally robust in terms of defending their ownership, formal approvals, additionality, permanence, prevention of leakage, and delivery of community and biodiversity benefits. The types of legal issues raised here are:

- Who owns the land?

\footnotetext{
${ }^{68}$ Martijn Wilder and Jennifer Crittenden, 'Bringing the Forest to Market: Structuring Avoided Deforestation Projects' (issues paper, Baker \& McKenzie, 2010), 7-8; see also, Martijn Wilder and Jennifer Crittenden, 'Bringing the Forest to Market: Structuring Avoided Deforestation Projects’ (2008) 3 Carbon and Climate Law Review 273.

${ }^{6}$ lbid 11.

${ }^{70}$ Ibid 8-9.

${ }^{71}$ Ibid $9-10$
} 
- Does the project developer have the right to use the land and, if so, what is the nature of that right? (that is, does the developer need freehold title, or a lease? Can the developer use the land for the time period necessary?)

- Are the planned REDD+ project activities regulated? What are the laws that govern the use of the project site?

- What are the developer's rights and obligations with respect to the local communities?

- If a foreign company is the developer's partner in the project, are there any restrictions imposed on the company by the government?

- How does the developer structure the project finance to cover start-up costs but also to mitigate risk?

Ultimately, strong legal frameworks can help to ensure that:

- The legal ownership of REDD+ project sites is clear;

- The legal ownership of carbon credits is clear and allocated according to transparent procedures within formal benefit-sharing arrangements;

- The vulnerabilities of forest-dependent peoples are recognised and addressed with formal legal protections;

- REDD+ credits are robust enough to be traded within emerging domestic emissions trading schemes; and

- The level of investment risk linked to regulatory uncertainty is significantly reduced.

It is important to note that these issues are not just relevant for a REDD+ financing model based on markets and carbon trading. Irrespective of what the investment is buying (whether it is a carbon credit, or a result), similar laws will apply to both the project's development and, if applicable, the commercial transaction. Fundamental issues regarding permissible project structures, land tenure and benefit-sharing must be resolved for any REDD+ programme to be successful. For example, under a 'mixed' model involving both fund and market structures, funds could purchase credits which would still need to be created through a robust legal construct (which provides certainty over land and carbon rights, fair and equitable treatment of indigenous landowners, and an assurance of permanence).

\section{Case study: REDD+ for mangroves, peatlands and other wetlands Implementing REDD+ in wetlands}

The Convention on Wetlands of International Importance Especially as Waterfowl Habitat ('Ramsar Convention') defines wetlands to include 'marsh, fen, peatland or water, whether natural or artificial, permanent or temporary, with water that is static or flowing, fresh, brackish or salt, including areas of marine water the depth of which at low tide does not exceed six metres'. ${ }^{72}$ Wetland ecosystems occupy approximately $5 \%$ of the earth's land area, ${ }^{73}$ including peatlands, peat swamp forests, mangroves, lakes, floodplains, marshes, lagoons, and rivers (refer to the Annex for detailed background information on wetlands).

Destruction of tropical wetlands is occurring faster than in any other tropical forest type, with clearing, draining and burning rapidly destroying wetlands. ${ }^{74}$ Wetlands can significantly contribute to carbon emissions, especially if drained or degraded. In addition, wetlands provide many other critical ecosystem services, including water quality improvement, flood mitigation, coastal protection (that is, from cyclones

\footnotetext{
72 Convention on Wetlands of International Importance Especially as Waterfowl Habitat, Ramsar, Iran, 2 Feb. 1971,996 UNTS 245, art 1(1) (entered into force 21 December 1975) ('Ramsar Convention').

${ }^{73}$ Shalu Adhikari, Roshan Bajracharaya and Bishal Sitaula, 'A Review of Carbon Dynamics and Sequestration in Wetlands' (2009) 2 Journal of Wetlands Ecology 42, 42, para 1. For a map of the global distribution of wetlands, see <http://soils.usda.gov/use/worldsoils/mapindex/wetlands.html>; for a map of the global distribution of mangroves, see <http://upload.wikimedia.org/wikipedia/commons/6/60/Giri.jpg>; for a map of the global distribution of peatlands, see <http://www.wetlands.org/DesktopModules/QuicklmageRepository/image.ashx?forceDownload= 0\&fileld $=5987>$.

${ }^{74}$ Andreas Langner et al, 'Land Cover Change 2002-2005 in Borneo and the Role of Fire Derived from MODIS Imagery' (2007) 13 Global Change Biology 2329; Jukka Miettinen and Soo Chin Liew, 'Degradation and Development of Peatlands in Peninsular Malaysia and in the Islands of Sumatra and Borneo Since 1990’ (2010) 21 Land Degradation \& Development 285; Jukka Miettinen and Soo Chin Liew, 'Status of Peatland Degradation and Development in Sumatra and Kalimantan' (2010) 39 Ambio 394; Chandra Giri et al, 'Status and Distribution of Mangrove Forest of the World Using Earth Observation Satellite Data’ (2011) 20 Global Ecology and Biogeography 154.
} 
and tsunamis) and habitat for many organisms. ${ }^{75}$ The importance of mangroves, peatlands and other wetlands as GHG sinks, therefore, draws attention to the potential role for REDD+ in addressing the destruction - and restoration - of these ecosystems. These landscapes provide unique challenges in terms of defining ownership/use rights (important when determining both the ownership and distribution of carbon rights) and in terms of what drives deforestation (which must be contemplated when considering how to achieve 'permanence' of carbon emissions within REDD+ project design).

\title{
Specific project-level issues related to mangroves, peatlands and other wetlands \\ Practical issues related to investment decisions
}

As noted by the International Union for the Conservation of Nature (IUCN):

\begin{abstract}
Wetlands have traditionally been perceived by policy-makers as 'wastelands' with no value unless drained. As argued by many, this pervading image has led to under-valuation of their potential, which, compounded by incentives to convert wetlands due to higher value uses, has often resulted in uncontrolled exploitation, conversion and degradation. The under-valuation of wetland resources has led to a situation where many wetlands areas lack a long history of ownership, clear tenure rights or any official delineation of property rights. ${ }^{76}$
\end{abstract}

Given that REDD+ is a mechanism to reward activities related to preserving forest carbon stores as an ecosystem service, the need to place an economic value on at least one aspect of wetlands might provide an opportunity to change the traditional view of wetlands described above.

For any landscape, the carbon sequestration potential needs to be assessed by a project developer in terms of its ability to generate carbon credits. For example, peatlands have a particularly high carbon storage, which could affect an investment decision influenced by the anticipated returns. The location and socioeconomic context of a wetland is also important - for example, mangroves in coastal areas could be vulnerable to sea-level rise, ${ }^{77}$ or clearing for the expansion of the fishing industry. Such issues can have a direct impact on the level of investment risk. If considered to be acceptable risks, they would nonetheless need to be managed within the project design.

Legal issues

As noted above, REDD+ projects need to operate under local regulatory frameworks. Therefore, when dealing with wetlands, laws pertaining to the use of waterways and the status of protected areas will be relevant to the project design.

Both the ownership and use rights of these ecosystems could be overlapping or unclear. The tenure arrangements of wetlands are relevant for establishing the project activities (or absence of activities), securing the 'permanence' of the emissions reduction credit generated (that is, the life of the project) and community engagement. However complicated, this will be an essential part of the due diligence process which has a bearing on the level of risk within an investment decision.

\section{Conclusion}

Commentators note that ${ }^{78}$ private sector finance will be required to scale-up REDD+ implementation; how to create incentives for private sector participation through a market-based approach, fund-based approach or a combination of the two is still under discussion. Nonetheless, as a starting point, the projects that have developed to supply credits to early forest carbon markets have provided a testing ground for a market-based approach, providing lessons for both policy-makers and future project proponents. In summary, these lessons include:

${ }^{5}$ William Mitsch et al, Wetland Ecosystems (John Wiley \& Sons, 2009); Sudip Mitra et al, An Appraisal of Global Wetland Area and its Organic Carbon Stock, (2005) 88 Current Science 25.

${ }^{76}$ Neil Adger and Cecilia Luttrell, The Values of Wetlands: Landscape and Institutional Perspectives (2000) 35 Ecological Economics 75, 75-76.

${ }^{77}$ Coastal wetlands are susceptible to sea level rise, which may change project boundaries or result in the loss of a project. In particular, 'Rapid, substantial changes in sea level pose significant threats to coastal and estuarine wetlands where back-lying lands are developed and sediment regimes have been disturbed ... Not only coastal and estuarine wetlands but community composition and aerial extent of communities of submerged aquatic vegetation (eg, sea grasses) may be affected by increased water depths, increased storm disturbances, reduced light penetration, and changing salinities'. See this paper on the VCS, VCS AFOLU Wetland Requirements (2012)

<http://bluecarbonportal.org/wp-content/uploads/downloads/2012/09/VCS-Blue-Carbon-Policy-Wksp_Ching.pdf>.

${ }^{78}$ Forum for the Future, above $\mathrm{n} 19$. 
- To be 'investment-grade', that is, to attract private sector investment, REDD+ projects must deliver carbon credits that represent additional and permanent emissions reductions, in addition to dealing with leakage and providing community and biodiversity benefits.

- Land tenure arrangements have a huge impact on forest carbon projects, affecting not only ownership of the carbon rights (and, therefore, the right to benefit from their monetisation) but also the success - and longevity - of project activities.

- National legal frameworks have an important role to play in designing and implementing projects by clarifying the rules regarding project approvals, land tenure, environmental benefits (including carbon) and community rights.

- Regardless of the model ultimately adopted for REDD + at the international and national levels, the same legal issues are likely to recur; if private sector finance for REDD+ is a priority, capacity building regarding the legal, institutional and administrative frameworks for REDD+ at the national level is essential.

- Clear processes for project approvals under the host country regulatory frameworks need to be developed in host countries; to date, in the absence of such approval processes, project developers use the VCS (which provides some guidance regarding what are considered to be acceptable requirements for creating credible carbon rights).

In Durban, the Conference of the Parties to the UNFCCC emphasised that market-based approaches should 'meet standards that deliver real, permanent, additional and verified mitigation outcomes'. ${ }^{79}$ In order to achieve these aims, domestic legal frameworks must:

- Clarify the legal nature of rights to and ownership of REDD+ land and carbon;

- Create the legal structures which will underpin a REDD+ market, where this model is chosen;

- Develop the requirements for credible compliance-grade credits which can be traded within domestic emissions trading regimes;

- Ensure that REDD+ credits represent a commercially viable commodity which allocates revenues equitably amongst stakeholders and fully respects the rights of indigenous peoples; and

- $\quad$ Minimise risk and investment uncertainty for private investors.

In the specific case of mangroves, peatlands and other wetlands, project-specific circumstances relevant to clarifying tenure arrangements and managing long-term risk to the project activities will need to be considered in context. However, if the intention is to develop 'investment-grade' projects that can attract private finance, the key issues highlighted above from early experience in forest carbon markets can provide insight into the role of both project design and regulatory frameworks in this process.

\footnotetext{
${ }^{79}$ UNFCCC Durban Platform, above n 3, para 79.
} 


\section{Annex: Background information about wetlands}

\section{What is a wetland?}

According to the Ramsar Convention, 'Wetlands are areas of marsh, fen, peatland or water, whether natural or artificial, permanent or temporary, with water that is static or flowing, fresh, brackish or salt, including areas of marine water the depth of which at low tide does not exceed six meters'. ${ }^{80}$ Wetland ecosystems occupy approximately five per cent of the earth's land area, and are found in all climatic zones and continents, with the exception of Antarctica. ${ }^{81}$ Such ecosystems include peatlands, peat swamp forests, mangroves, lakes, floodplains, marshes, lagoons, and rivers. ${ }^{82}$ Some types of wetlands are described in more detail below:

- Peatlands: 'Peatlands are ecosystems where - under conditions of permanent water saturation - dead and decaying plant material has accumulated to form a thick organic soil layer (peat). Peatlands are the most concentrated and most important reservoirs of terrestrial carbon'. ${ }^{83}$ More specifically, soils that are 'rich in organic matter that are prone to waterlogged conditions undergo a biochemical process under the influence of aerobic microorganisms which act on the organic matter at the soil-water interface and slowly converts it to peat. Gradually the $\mathrm{pH}$ reduces because of slow microbial activity on the decomposition of the organic soils which produces organic acids. ... [T] he waterlogged conditions and low pH creates anaerobic conditions which, in turn, completely retards decomposition and preserves the peat soils'. ${ }^{84}$

- Peat Swamp Forests: These are forested peatlands (see the description above), distinct from other peatlands, because 'In natural peat swamp forests, the forest provides the plant material and facilitates the wet conditions for peat formation, carbon sequestration and carbon storage' ${ }^{85}$

- Mangroves: 'There are about 80 different species of mangrove trees', which 'grow in areas with lowoxygen soil, where slow-moving waters allow fine sediments to accumulate. Mangrove forests only grow at tropical and subtropical latitudes near the equator because they cannot withstand freezing temperatures. Many mangrove forests can be recognized by their dense tangle of prop roots. ... This tangle of roots allows the trees to handle the daily rise and fall of tides. ... The roots also slow the movement of tidal waters, causing sediments to settle out of the water and build up the muddy bottom. Mangrove forests stabilize the coastline, reducing erosion from storm surges, currents, waves, and tides. The intricate root system of mangroves also makes these forests attractive to fishes and other organisms seeking food and shelter from predators'. ${ }^{86}$

- Palustrine Wetlands: 'Palustrine wetlands are inundated grasslands, inundated plains or swamps with an average depth of less than $2 \mathrm{~m}$ and aquatic vegetation covering around $30 \%$ of the surface area. This type of wetland includes permanently inundated areas, such as inundated shrub and grasslands, reed swamps, and cultivation fields' ${ }^{87}$

- Lacustrine Wetlands: 'Lacustrine wetlands include natural or man-made lakes, swamps, ponds or reservoirs that are over $80000 \mathrm{~km}^{2}$ in size, both permanent and seasonal; those that are smaller than $80000 \mathrm{~km}^{2}$ with a depth of over $2 \mathrm{~m}$ and aquatic vegetation covering less than $30 \%$ of the surface area; those with permanent water, such as natural reservoirs, fish ponds, sewage ponds, cooling ponds and abandoned mines; and those with water in some seasons'.$^{88}$

- $\quad$ Riverine Wetlands: 'Riverine wetlands have a clearly visible riparian system and include rivers, canals and streams with permanent flow or seasonal flow; floodplains; inundated grasslands/paddy fields;

\footnotetext{
${ }^{80}$ Ramsar Convention, above n.72.

${ }^{81}$ See Adhikari et al, above $\mathrm{n} 73$, para 1. For a map of the global distribution of wetlands, see <http://soils.usda.gov/ use/worldsoils/mapindex/wetlands.html>; for a map of the global distribution of mangroves, see <http://upload. wikimedia.org/wikipedia/commons/6/60/Giri.jpg>; for a map of the global distribution of peatlands, see <http: / / www. wetlands.org/DesktopModules / QuicklmageRepository/image.ashx?forceDownload=0\&fileld=5987>.

${ }^{82}$ See a photographic slideshow of the different kinds of wetlands by Wetlands International at <http://www.wetlands.org/Whatarewetlands/tabid/202/AlbumID/11392-86/Default.aspx>

${ }^{83}$ Iwan Tri Cahyo Wibisono et al, 'Peatlands in Indonesia's National REDD+ Strategy' (Wetlands International, 2011) 8, box 1 <http:/ / www.wetlands.org/LinkClick.aspx?fileticket=9Nesl6BCI1U\%3d\&tabid=56>.

${ }^{84}$ Wetlands International, Information Pack on Conservation and Management of Peat Swamp Forests, 1, para 1 <http://www. wetlands.org/LinkClick.aspx?fileticket=\%2bFln9c0N384\%3d\&tabid=56 (last accessed 26 Oct. 2012)>.

${ }^{85}$ Wibisono et al, above $\mathrm{n} 83,8$, box 1 .

${ }^{86}$ National Oceanic and Atmospheric Administration, Mangrove Forests (2011) <http://oceanservice.noaa.gov/facts/ mangroves.html>.

${ }^{87}$ Narong Veeravaitaya et al, 'The Legal and Institutional Basis for Wetlands Governance in Thailand and the Economic Value of Wetlands in Surin and Buri Ram Provinces' (Northeast Thailand, WorldFish Centre, 2005) 158 <http://www. worldfishcenter.org/resource_centre/WetlandsGovernance.pdf>.

${ }^{88}$ Ibid.
} 
swamp shrub lands; seasonal ponds of over $80000 \mathrm{~km} 2$ in size; seasonal ponds of less than $80000 \mathrm{~km} 2$ in size; and inundated plains/flooded riverbanks'. ${ }^{89}$

Notably, there may be important environmental distinctions to make even within the aforementioned wetland categories. For instance, 'Peatlands that receive most of their water from precipitation are referred to as ombrotrophic peatlands or bogs, whereas peatlands that are mainly fed by water that has been into contact with mineral soil are referred to as minerotrophic peatlands or fens'. ${ }^{90}$ Also, wetland categories are not concrete or consistent across literature, law or policy - there are many ambiguities and areas of overlap between wetlands and other ecosystems (for example, should a peat swamp forest be considered a forest or a wetland?) and between various wetland sub-categories. One study of Malaysia's peatlands demonstrates this challenge, noting that 'Previous studies of peatlands in Malaysia have used different or interchangeable definitions of 'peatland' or 'peat soil'... In some reports, it is unclear whether area estimates are for peat swamp forest, peatlands, or peat soils'. ${ }^{91}$

\section{The significance of wetlands}

- Carbon Sequestration and Storage: There is increasing evidence that inland and coastal wetlands are important in the global carbon cycle as ecosystems that provide sequestration and long-term storage of carbon dioxide $\left(\mathrm{CO}_{2}\right) .{ }^{92}$ The 'entrance of carbon dioxide into a wetland system is via photosynthesis by wetland plants giving it the ability to alter its concentration in the atmosphere by sequestrating this carbon in the soil'. ${ }^{93}$ Wetlands may also 'trap carbon rich sediments from watershed sources', storing additional carbon. ${ }^{94}$ Notably, not all wetlands store carbon equally - tropical wetlands store roughly $80 \%$ more carbon than temperate wetlands according to comparisons between wetland ecosystems in Costa Rica and Ohio. ${ }^{95}$

- Carbon Release: However, 'many wetlands, especially boreal and tropical peatlands, have highly labile carbon and these wetlands may release carbon if water level is lowered or management practices results in oxidation of soils'. ${ }^{96}$ Wetlands 'may also release dissolved carbon into adjacent ecosystems'. ${ }^{97}$ In this way, wetlands may also significantly contribute to carbon emissions, especially if drained or degraded. The 'degradation of wetlands and disturbance of their anaerobic environment' leads to a 'higher rate of decomposition of ... carbon', thus releasing greenhouse gases into the atmosphere. ${ }^{98}$

- Methane Release: Wetlands are also important methane sinks and sources-it is estimated that wetlands emit approximately $20-25 \%$ of current global methane emissions. ${ }^{99}$ Wetlands may 'contribute in the release of methane to the atmosphere even in the absence of climate change'. ${ }^{100}$

- Other Services: Wetlands provide many other critical ecosystem services as well, including water quality improvement, flood mitigation, coastal protection (ie, from cyclones and tsunamis), and habitat for many organisms. ${ }^{101}$ The table below lists key wetland functions and notes key metrics for monitoring and quantifying wetland services. ${ }^{102}$

89 Ibid

${ }^{90}$ Juul Limpens, 'Peatlands and the Carbon Cycle: From Local Processes to Global Implications-A Synthesis' (2008) 5 Biogeosciences 1476, para 4.

91 Wetlands International, A Quick Scan of Peatlands of Malaysia (2010) 22, para 1 <http://www.wetlands.org/ LinkClick.aspx?fileticket=6x6fRzfiNkk\%3d\&tabid=56>.

92 Steven Bouillon, 'Storage Beneath Mangroves' (2011) 4 Nature Geoscience 282; Daniel Donato et al, 'Mangroves Among Most Carbon-Rich Forests in the Tropics', (2011) 4 Nature Geoscience 293; William Mitsch et al, 'Wetlands, Carbon, and Climate Change' [2012] Landscape Ecology; Mary Rose Posa et al, 'Biodiversity and Conservation of Tropical Peat Swamp Forests' (2011) 61 Bioscience 49.

${ }_{93}$ Adhikariet al, above $\mathrm{n} 73,44$, para 7.

94 Ibid.

${ }^{95}$ Blanca Bernal, 'Carbon Pools and Profiles in Wetland Soils: The Effect of Climate and Wetland Type' (MS thesis for Ohio State University, 2008).

${ }^{96}$ Adhikari et al, above $\mathrm{n} 73,44$, para 7

97 Ibid.

98 Ibid 44, para 10.

99 Stephen Whalen, 'Biogeochemistry of Methane Exchange Between Natural Wetlands and the Atmosphere’ (2005) 22 Environmental Engineering Science 73.

${ }^{100}$ Adhikari et al, above $\mathrm{n} 73,44$, para 7.

101 William Mitsch et al, Wetland Ecosystems (John Wiley \& Sons, 2009); Sudip Mitra et al, 'An Appraisal of Global Wetland Area and its Organic Carbon Stock' (2005) 88 Current Science 25.

102 Daniel Murdiyarso et al (eds), Tropical Wetlands for Climate Change Adaptation and Mitigation: Science and Policy Imperatives with Special Reference to Indonesia (Centre for International Forestry Research [CIFOR], 2012 ) 2. 
Table A1: Ecosystem functions, goods and services that can be quantified for tropical wetland forests ${ }^{103}$

\begin{tabular}{|c|c|c|}
\hline Function & Goods and services & Quantifier \\
\hline Water regulation & Water supply to local communities & $\begin{array}{l}\text { Water yield: } \mathrm{m}^{3} \text { fresh water/household/year; } \\
\text { seasonal discharge/baseflow }\left(\mathrm{m}^{3} / \mathrm{s}\right)\end{array}$ \\
\hline Climate regulation & Atmospheric $\mathrm{CO}_{2}$ sequestration & MG carbon captured/ha/year \\
\hline $\begin{array}{l}\text { Breeding/nursing habitat for } \\
\text { reef and offshore fish }\end{array}$ & Fishery production/protein source & Annual catch (mg/year) \\
\hline $\begin{array}{l}\text { Wave energy attenuation } \\
\text { substrate stabilisation }\end{array}$ & $\begin{array}{l}\text { Coastal defence/protection of } \\
\text { settlements and infrastructure }\end{array}$ & $\begin{array}{l}\text { Number of households protected, dyke } \\
\text { maintenance costs avoided etc. }\end{array}$ \\
\hline Biodiversity conservation & $\begin{array}{l}\text { Habitat for endangered, threatened } \\
\text { or vulnerable species }\end{array}$ & Number of species protected \\
\hline Timber production & High value timber & $\mathrm{m}^{3}$ timber/ha/year \\
\hline Non-timber forest products & $\begin{array}{l}\text { Fruits, seeds, palms, ferns, honey, } \\
\text { fungi, medicinal plants, fish, crabs, } \\
\text { etc. }\end{array}$ & $\begin{array}{l}\text { Economic value: monetary unit/year; kg } \\
\text { product consumed/year }\end{array}$ \\
\hline Cultural/heritage & Use of traditional religious sites & Frequency and number of people using site \\
\hline Ecotourism & $\begin{array}{l}\text { Boat rides, wildlife viewing, } \\
\text { camping, etc. }\end{array}$ & $\begin{array}{l}\text { Number of tourists/year; income generated } \\
\text { from tourism }\end{array}$ \\
\hline
\end{tabular}

Note: 'Quantifier' refers to units which can be used to measure goods and/or services

\section{Basic threats to wetlands}

Deforestation in tropical wetlands is occurring faster than in any other tropical forest type, with clearing, draining, and burning rapidly destroying wetlands. ${ }^{104}$

- Clearing: In Southeastern Asia, 'Prominent land uses on organic wetland soils include agriculture (oil palm, rice, sago palm and vegetable crops), silviculture (timber estates, rubber plantations) and aquaculture (shrimp and fish ponds; largely confined to converted mangroves)' ${ }^{105}$ Additionally, wetlands are converted for settlements, land speculation and infrastructure development. ${ }^{106}$ Although historically mangroves were threatened by extraction for fuel, tannin and charcoal production, ${ }^{107}$ shrimp and fish aquaculture is increasingly playing a role in the destruction of mangroves across Southeastern Asia. ${ }^{108}$

- Draining: Natural $\mathrm{CO}_{2}$ emissions from peat decomposition are exacerbated by draining peatlands. ${ }^{109}$ When wetlands are drained, 'aerobic conditions stimulate organic matter decomposition and former wetland carbon sinks can emit large amounts of stored carbon into the atmosphere'. ${ }^{110}$ Emissions continue 'as long as the water table is artificially lowered or until active carbon resources are exhausted'. ${ }^{111}$ Notably, 'Wetlands in the humid tropics are particularly sensitive to rapid carbon oxidation and loss from disturbance because the environmental controls on decomposition (temperature and moisture) are optimum'. Draining is often encouraged by selective logging, wherein 'canals are dug to transport cut timber', and farming, as 'most common agricultural uses on peatlands require drainage for survival of planted species'. ${ }^{112}$

- Burning: Once drained, many peatlands are also intentionally burned during the conversion process of swamp to agricultural land. ${ }^{113}$ Drained and degraded peatlands are especially susceptible to fires (both intentional or accidental), which release large amounts of carbon in a very short period of time. ${ }^{114}$

103 Mudiyarso et al, above n 102, 2.

104 Langner et al, above n 74; Miettinen and Soo, above n 74; Miettinen and Soo, above n 74 ; Giri et al, above $n 74$.

${ }^{105}$ Murdiyarso et al, above n 102, 10, para 2.

106 Ibid.

107 Armando De La Cruz, 'Wetland Uses in the Tropics and Their Implications on the World Carbon Cycle’ (1982) 2 Wetlands 1.

${ }^{108}$ Daniel Alongi, 'Present State and Future of the World's Mangrove Forests' (2002) 29 Environmental Conservation 331; Norm Duke, ‘A World Without Mangroves?’ (2007) 317 Science 41.

${ }^{109}$ Aljosja Hooijer et al, ‘Assessment of $\mathrm{CO}_{2}$ Emissions from Drained Peatlands in SE Asia' (Delft Hydraulics Technical Report Q3943, 2006); Jörn Germer and Joachim Sauerborn, 'Estimation of the Impact of Oil Palm Plantation Establishment on Greenhouse Gas Balance’ (2007) 10 Environment, Development and Sustainability 697.

${ }^{110}$ Murdiyarso et al, above n 102,10, para 2.

111 Ibid 5, para 2.

112 lbid.

113 Ibid 5, para 3.

114 Susan Page et al, 'The Amount of Carbon Released from Peat and Forest Fires in Indonesia During 1997' (2002) 420 Nature 61; Jukka Miettinen et al, 'Two Decades of Destruction in Southeast Asia's Peat Swamp Forests' (2012) 10

Frontiers in Ecology and the Environment 124; Guido Van der Werf et al, 'Climate Regulation of Fire Emissions and 
Fires may also spread below ground through peatlands, making them difficult to extinguish. ${ }^{115}$ The risk of natural or out of control fires may additionally be exacerbated by El Niño drought events. ${ }^{116}$

\section{Conserving and restoring wetlands (peatland focus)}

Wetlands International suggests four main strategies for addressing the destruction or degradation of peatlands. ${ }^{117}$ Notably, these strategies apply generally to wetlands under which peatlands are classified. The strategies include:

1. Secure undrained peatlands through conservation and paludiculture: Keeping peatlands wet allows for the accumulation and storage of carbon; thus, refraining from cultivation completely (conservation) is the best option for eliminating the potential for GHG emissions. ${ }^{118}$ However, paludiculture is also an option. This is a land management technique that leaves peatlands wet - by planting crops that do not require drained lands - and intact - by harvesting only the aboveground parts of vegetation (for example, crops could include berries or mushrooms). ${ }^{119}$

2. Rewet and restore drained peatlands: Rewetting drained peatlands 'involves the partial or entire reversal of former anthropogenic drainage by elevating the average annual water table', aiming to achieve 'permanent water saturation of the entire peat body'. ${ }^{120}$ Key considerations for rewetting include water availability, land use, relief (variation in elevation and slope), and tree growth (trees may enhance evapotranspiration and affect micro-climates in wetlands). ${ }^{121}$ Restoring peatlands includes rewetting, but may also include other practices aimed at 'revitalizing the peat accumulation process'. ${ }^{122}$ Key factors here are peat hydraulic conditions (water flow, absorption and repulsion), relief, and vegetation. ${ }^{123}$

3. Adapt the management of drained peatlands in productive use: Where peatlands cannot be rewetted, management may instead focus on: 1) minimising drainage, 2) selecting crops adapted to high soil moisture, 3) avoiding ploughing, 4) cultivating crops that provide shade, thus reducing surface temperatures and slowing peat oxidation, and 5) limiting fertilisers that increase peat oxidation and result in large nitrous oxide emissions. ${ }^{124}$

4. Control hazards on abandoned drained peatlands: Fire control on abandoned drained peatlands may include: 1) monitoring, 2) establishing water sources for fire fighting, 3) establishing sufficient fire brigades, 4) providing training in fire prevention, suppression, and disaster management, and 5) developing adequate communication structures and coordinated responses to disasters. ${ }^{125}$

Deforestation in Equatorial Asia' (2008) 23 Proceedings of the National Academy of Sciences of the United States of America 20350.

${ }^{115}$ Uwe Ballhorn et al, 'Derivation of Burn Scar Depths and Estimation of Carbon Emissions with LIDAR in Indonesian Peatlands' (2009) 106 Proceedings of the National Academy of Sciences of the United States of America 21213.

${ }^{116}$ Florian Siegert et al, 'Increased Damage from Fires in Logged Forests During Droughts Caused by El Niño' (2001) 414 Nature 437; Van der Werf et al, above $\mathrm{n} 113$.

117 Hans Joosten et al (eds), Peatlands-Guidance for Climate Change Mitigation by Conservation, Rehabilitation and Sustainable Use (FAO and Wetlands International, 2012).

118 Ibid 11.

119 Ibid 11-12.

120 Ibid 14, para 4.

${ }^{121}$ Ibid 15.

122 Ibid 15, para 3.

123 Ibid 15, para 4

124 Ibid 16-17.

125 Ibid 18. 